\title{
Establishment of prize for AAOMFR best article
}

\author{
Junichi Asaumi ${ }^{1}$
}

Published online: 22 December 2018

(c) Japanese Society for Oral and Maxillofacial Radiology and Springer Nature Singapore Pte Ltd. 2018

A new award for the best published article was established by the Asian Academy of Oral and Maxillo-Facial Radiology (AAOMFR). The name of the award is the Prize for AAOMFR Best Article:

This prize was proposed and developed by Min-Suk Heo, editor-in-chief of Imaging Science in Dentistry.

The editor-in-chief of each official journal (Imaging Science in Dentistry and Oral Radiology) selects the best articles from the AAOMFR official journals published between the previous and present Asian Congress of Oral and Maxillo-Facial Radiology (ACOMFR).

One of the authors of each article should attend the AAOMFR General Assembly (GA) of ACOMFR to accept the award. If none of the authors is able to attend the GA for official reasons, the editor may decide not to give the award.

The authors should be members of the AAOMFR and belong to Aisian Institution. If candidates are not AAOMFR members, the editor-in-chief will ask them to become so. If they become AAOMFR members, they are eligible for the award. If they do not wish to join the AAOMFR, another candidate may be selected by the editor-in-chief.

Plaques and certificates will be prepared according to the number of authors of the article, and the prize money is US\$500.

The sponsor of this prize is Cybermed Inc.
Awards at the 12th ACOMFR in Mumbai were as follows. The 2018 prize for best article was given to these two articles:

Imaging Science in Dentistry

Ibrahim K. Ali, Kaustubh Sansare, Freny R. Karjodkar, Kavita Vanga, Prashant

Salve, Ajinkya M. Pawar

"Cone-beam computed tomography analysis of accessory maxillary ostium and

Haller cells: Prevalence and clinical significance"

Imaging Science in Dentistry 2017; 47(1): 33-37

Oral Radiology

Yoshiko Ariji, Akitoshi Katsumata, Ryota Kubo, Akira Taguchi, Hiroshi Fujita,

Eiichiro Ariji

"Factors affecting observer agreement in morphological evaluation of

mandibular cortical bone on panoramic radiographs"

Oral Radiology 2017; 33(2): 117-123

We are always looking forward to reading your excellent articles.

Publisher's Note Springer Nature remains neutral with regard to jurisdictional claims in published maps and institutional affiliations.

Junichi Asaumi

asaumi@md.okayama-u.ac.jp

1 Okayama University, Okayama, Japan 